\title{
Research on Single Input and Regulated Multiple Output Isolated Dc-Dc Soft Deviceing Converter
}

\author{
J.Sivavara Prasad, K.R.L.Prasad, G.Nageswara Rao
}

\begin{abstract}
In this paper, in order to reduce the space occupied by individual DC-DC converter systems, the two-level single input multiple output isolated DC-DC converter is proposed for generating (2n-1) outputs where ' $n$ ' is number of legs. The first and second output voltages are controlled based on the control of duty cycles of two half bridge asymmetrical topologies and third output voltage is controlled based on phase shift control of two half bridge asymmetrical topologies. The efficiency of the proposed single input multiple output two-level isolated DC-DC converter has been compared with existing single input multiple output two-level DC-DC converter to realize the proposed work.
\end{abstract}

Keywords: Pulse width modulation, switching losses, Zero voltage switching dc-dc converter, controlled multiple output.

\section{INTRODUCTION}

The two-level single input multiple output isolated DC-DC topologies were proposed in order to reduce the space occupied by individual DC-DC converter systems. The dc-dc multiple-output topologies are mainly used in electronic equipments such as PC appliance, military and industrial applications. For designing the conventional dc-dc multiple output topologies, how to regulate multiple outputs is the main issue. In order to regulate all the output voltages against load and line variation in dc-dc multiple-output topologies, post regulation has been mainly used in [1]-[4]. There are various ways to make post regulation. In low output current applications, the linear voltage regulation is used. In high output current applications, the magamp post regulation proposed in [1]-[4], which makes the advantage of ability of handling high current and high efficiency. However, the large size and high cost of magamp post regulation has limited its application. Later, the synchronous-device post regulator has been developed in [5]-[9] is other way need for high output current applications, which utilizes the device as the post regulation. The synchronous-device post regulator has many features over magamp post regulation, such as easier remote on/off control implementation, easier over current protection, and smaller size.

DC-DC Multiple output topologies by pulse width and frequency modulations control were proposed in [10], in

Revised Version Manuscript Received on July 10, 2019.

J.Sivavara Prasad, L B R College of Engineering, Mylavaram, Andhra Pradesh India.

(e-mail: janapatisivavaraprasad@gmail.com)

K.R.L.Prasad, L B R College of Engineering, Mylavaram, Andhra Pradesh India.

(e-mail: saiprasad645@yahoo.co.in)

G.Nageswara Rao, L B R College of Engineering, Mylavaram, Andhra Pradesh India.

(e-mail: gnrgudipudi@gmail.com) which the auxiliary output is controlled through the switching frequency and the main output is PWM controlled. The PWM frequency modulation control method is suitable to two-output applications only and due to variable-frequency control, the magnetic component is not easy to optimize. The other method used in dc-dc multiple-output topologies is parallel regulation in [11], it adds a adjustable voltage source in auxiliary circuit. By tuning the voltage of the adjustable voltage source, the auxiliary output is controlled. However, this method is very costly and precisely controlled. The PWM-pulse delay control technique was implemented to the $\mathrm{dc}-\mathrm{dc}$ multiple-output topologies in [12]. It has been proved to have the feature of ability to produce controlled outputs but the structure is complicated and it require more number of control devices for multiple outputs.

In this research work, to overcome the limitations in the existing multi level outputs, the single input controlled two-level multiple output isolated DC-DC converter is proposed for generating ( $2 n-1)$ outputs, here ' $n$ ' is number of legs. This topology is very simple and attractive due to less number of control devices.

This research paper is divided into three sections. The introduction is discussed in section 1 . The characteristics of DC-DC multiple output converter, operating modes, realization of soft mechanism, design equations and results of two-level single input controlled multiple output isolated DC-DC converter are presented in section 2 . The results and conclusion of the work are discussed in section 3 and 4 .

\section{ZVS MULTIPLE OUTPUT ISOLATED DC-DC CONVERTER:}

The circuit diagram of single input controlled three output isolated DC-DC converter is shown in Figure 1. The second output is used for low voltage and high current mode of applications. The three output voltages are controlled based on the control devices in the primary side of inverter. The voltages $\mathrm{V}_{\mathrm{AB}} \& \mathrm{~V}_{\mathrm{CD}}$ are the voltage across transformers $\mathrm{T}_{1}$ \& $\mathrm{T}_{2}$ and the voltage $\mathrm{V}_{\mathrm{AC}}$ is the voltage of transformer $3 \&$ blocking capacitor $C_{b}$ respectively. The output voltage $V_{01}$ is controlled by the duty cycle control of asymmetrical half ridge converter $S_{1} \& S_{4}$ and capacitors $C_{1} \& C_{2}$. The output voltage $\mathrm{V}_{02}$ is controlled by the duty cycle control of other asymmetrical half bridge converter $\mathrm{S}_{3} \& \mathrm{~S}_{2}$ and capacitors $\mathrm{C}_{3} \& \mathrm{C}_{4}$. The output voltage $\mathrm{V}_{03}$ is controlled based on phase shift of two asymmetrical half bridge topologies. All the control devices in the converter are operating under ZVS, hence this converter topology is suitable for high efficiency and high frequency applications. 


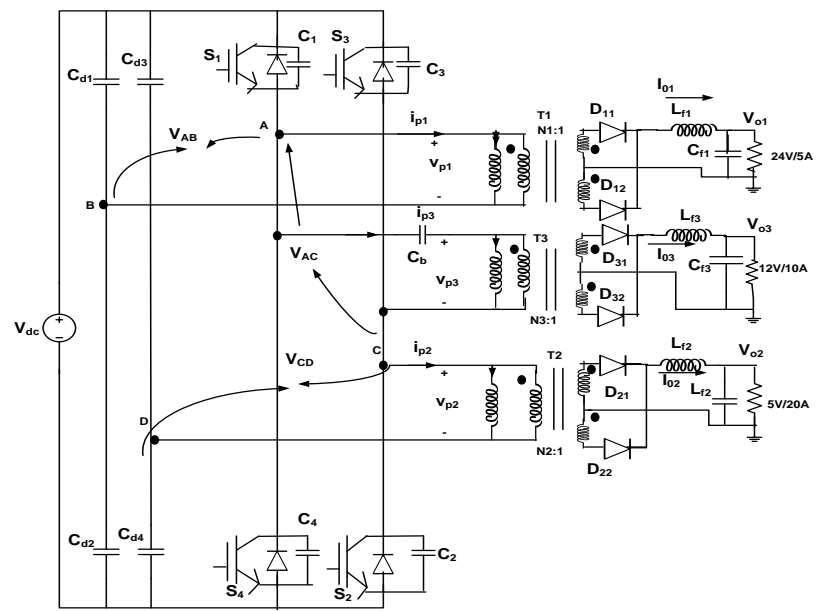

Figure 1: Controlled Three terminal outputs of ZVS isolated DC-DC converter

The Figure 2 shows the control signals of the multiple output converter. The three output ZVS DC-DC converter consists of two asymmetrical half bridge topologies connected to three single phase transformers.

Table 1 shows the comparison of proposed single input controlled three output isolated DC-DC converter with the conventional single input three output isolated DC-DC converter [5]. From table 1, it is clear that, the no. of control devices used in the proposed converter is less as compared to the existing converter and design of transformer is simpler in the proposed one. Hence, the deviceing losses are reduced and efficiency of the conversion system has been improved.

Table 1: Comparison of Proposed converter with other multiple output converter

\begin{tabular}{|c|c|c|}
\hline Type of Element & $\begin{array}{l}\text { Single } \\
\text { input three } \\
\text { output } \\
\text { DC-DC } \\
\text { converter } \\
\text { topology [5] }\end{array}$ & $\begin{array}{l}\text { Proposed } \\
\text { single input } \\
\text { three output } \\
\text { DC-DC } \\
\text { Converter } \\
\text { Topology }\end{array}$ \\
\hline Control devices & $2 n+1$ & $n+1$ \\
\hline Diodes & $3 n-1$ & $3 n+1$ \\
\hline Gate-Amp & $2 n+1$ & $n+1$ \\
\hline $\begin{array}{c}\text { Transformer } \\
\text { Design }\end{array}$ & Complex & Simple \\
\hline Deviceing Losses & High & Low \\
\hline \multicolumn{2}{|l|}{$\begin{array}{l}\text { Where " } n \text { "is the number of } \\
\text { output voltages, } n=3\end{array}$} \\
\hline
\end{tabular}

Where $V_{d c}$ is the input voltage, $\mathrm{k}_{1}$ is the first asymmetrical converter duty cycle and $\mathrm{N}_{\mathrm{T} 1}$ is the turns ratio of transformer $\mathrm{T}_{1}$.

The voltage gain of $1^{\text {st }}$ output voltage to the input dc voltage is,

$G_{01}=\frac{V_{01}}{V_{\mathrm{dc}}} \cdot \mathrm{N}_{\mathrm{T} 1}=2 \mathrm{k}_{1}\left(1-\mathrm{k}_{1}\right)$

From the above equation it is clear that the voltage gain $G_{01}$ is maximum at $\mathrm{k}_{1}=0.5$.

The $2^{\text {nd }}$ output voltage $V_{02}$ is

$V_{02}=2 \cdot V_{d c} \cdot \mathrm{k}_{2} \cdot\left(1-\mathrm{k}_{2}\right) \cdot \frac{1}{N_{\mathrm{T} 2}}$

Where $\mathrm{k}_{2}$ the second asymmetrical converter duty cycle and $\mathrm{N}_{\mathrm{T} 2}$ is the turn's ratio of transformer $\mathrm{T}_{2}$.

The voltage gain of $2^{\text {nd }}$ output voltage to the input dc voltage is,

$$
\mathrm{G}_{02}=\frac{\mathrm{v}_{02}}{\mathrm{v}_{\mathrm{dc}}} \cdot \mathrm{N}_{\mathrm{T} 2}=2 \mathrm{k}_{2}\left(1-\mathrm{k}_{2}\right)
$$

From the above equation, it is clear that the voltage gain $G_{02}$ is maximum at $\mathrm{k}_{2}=0.5$.

The third output voltage $V_{03}$ depends on the duty cycles of two asymmetrical half bridge topologies $\mathrm{k}_{1}$ and $\mathrm{k}_{2}$. If $\mathrm{k}_{1}$ is greater than $\mathrm{k}_{2}$,

$$
\begin{array}{r}
V_{03}=V_{d c} \cdot\left(\mathrm{k}_{1}+\mathrm{k}_{2}-2 \cdot d\right) \cdot \frac{1}{N_{\mathrm{T} 3}}+V_{d c} \cdot\left(\mathrm{k}_{1}\right. \\
\left.-\mathrm{k}_{2}\right) \cdot\left(1-2 \cdot \mathrm{k}_{1}+2 \cdot d\right) \frac{1}{N_{\mathrm{T} 3}}
\end{array}
$$

If $\mathrm{k}_{1}$ is less than $\mathrm{k}_{2}$ then $V_{03}$ becomes 


$$
\begin{array}{r}
V_{03}=V_{d c} \cdot\left(\mathrm{k}_{1}+\mathrm{k}_{2}-2 \cdot d\right) \cdot \frac{1}{N}_{\mathrm{T} 3}+V_{d c} \cdot\left(\mathrm{k}_{2}\right. \\
\left.-\mathrm{k}_{1}\right) \cdot\left(1-2 \cdot \mathrm{k}_{2}+2 \cdot d\right) \frac{1}{N_{\mathrm{T} 3}}
\end{array}
$$

Where $d$ is the phase shift of devices $S_{1}$ to device $S_{4}$ and $N_{\mathrm{T} 3}$ is the turns ratio of transformer $\mathrm{T}_{3}$.

Both the terms in equations (5) and (6) are the coefficients of $V_{d c} \cdot \frac{1}{N_{T 3}}$. Now for the given $\mathrm{V}_{\mathrm{dc}}$ and turns ratios $N_{\mathrm{T} 1}=4$, $N_{\mathrm{T} 2}=38$ and $N_{\mathrm{T} 3}=25$, the term $\left(k_{1}-\mathrm{k}_{2}\right) \cdot\left(1-2 \cdot \mathrm{k}_{1}+2 \cdot d\right)$ is very small compared to $\left(k_{1}+\mathrm{k}_{2}-2 . d\right)$ term and hence it is neglected. So, the $3^{\text {rd }}$ output voltage becomes,

$V_{03}=V_{d c} \cdot\left(\mathrm{k}_{1}+\mathrm{k}_{2}-2 \cdot d\right) \cdot \frac{1}{N}_{\mathrm{T} 3}$

\subsection{Operating modes of the proposed converter:}

The following assumptions are considered in the operation of the proposed converter.

$>$ The duty cycles $k_{1}$ and $k_{2}$ are both near 0.5 , so the voltage across $\mathrm{C}_{\mathrm{b}}$ is $\left(k_{1}-\mathrm{k}_{2}\right) \cdot \mathrm{V}_{\mathrm{dc}}$ (when duty cycle $k_{1}$ is more than $k_{2}$ ) or $\left(k_{2}-\mathrm{k}_{1}\right) . \mathrm{V}_{\mathrm{dc}}$ (when duty cycle $k_{2}$ is more than $k_{1}$ ) and is small compared to $\mathrm{V}_{\mathrm{dc}}$ and therefore will be ignored.

$>$ The control devices $\mathrm{S}_{1} \& \mathrm{~S}_{4}$ are operating under ZVS based on the usage of energy stored in output inductor of $3^{\text {rd }}$ output. The control devices $S_{2} \& S_{3}$ are operating under ZVS based on the energy stored in leakage inductance of transformers $\mathrm{T}_{2}$ and $\mathrm{T}_{3}$.

$>$ The voltage across capacitors $\mathrm{C}_{\mathrm{d} 1}-\mathrm{C}_{\mathrm{d} 4}$ and $\mathrm{C}_{\mathrm{b}}$ are constant by selecting large values of capacitances.

$>$ The output inductors are large enough to make the output as constant current sources.

The voltage and current operational waveforms of proposed three output isolated DC-DC converter is shown in Figure 3.

\section{Mode $1(t 0-t 1)$ :}

Before mode 1, the transformers 1 and 2 are transmitting power to load through the devices $S_{1}$ and $S_{3}$, whereas the secondary output voltage of transformer 3 is freewheels. At the time $t=t_{0}$, the device $S_{3}$ is turned off under ZVS. The primary current $i_{p 2}$ and $i_{p 3}$ will charge the capacitor $\mathrm{C}_{3}$ and discharge capacitor $\mathrm{C}_{2}$. The primary voltage $\mathrm{V}_{\mathrm{AC}}$ comes to positive, then the current in the diode $\mathrm{D}_{31}$ starts rising from zero value. The voltage across transformer $T_{3}$ is clamped to zero due to the conduction of diodes $\mathrm{D}_{31}$ and $\mathrm{D}_{32}$ simultaneously, as shown in the Figure 4.

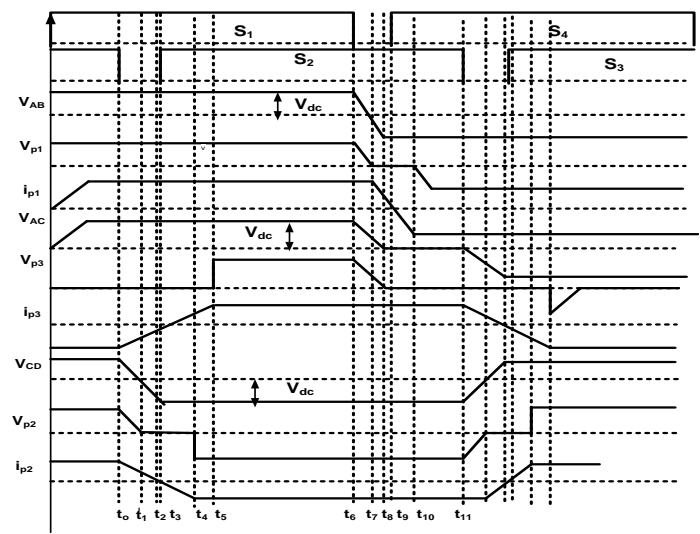

Figure 3: Voltage and current waveforms of three output isolated DC-DC converter

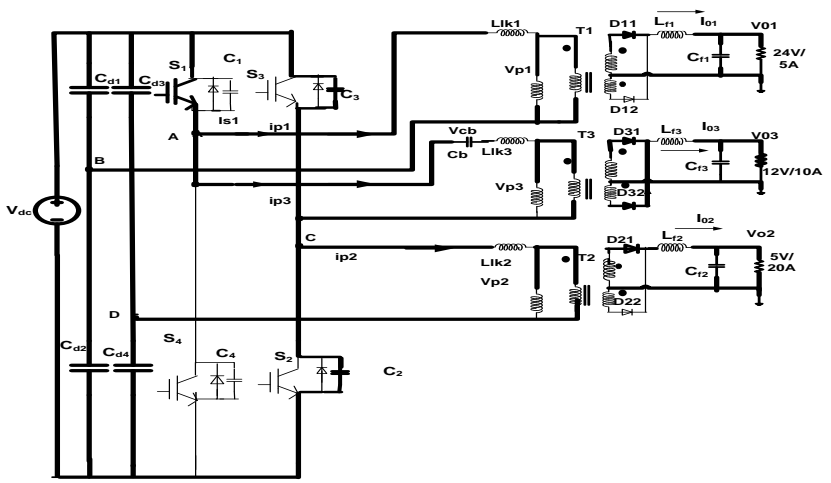

Figure 4: Mode '1' operation

\section{Mode $2(t 1-t 2)$ :}

At time $\mathrm{t}=\mathrm{t}_{1}$, the capacitor $\mathrm{C}_{2}$ is discharged to $\left[\mathrm{k}_{2} \cdot \mathrm{V}_{\mathrm{dc}}\right]$. The voltage $\mathrm{V}_{\mathrm{CD}}$ becomes zero if the voltage across capacitor $\mathrm{C}_{2}$ is $\left[k_{2} \cdot\left(\mathrm{V}_{\mathrm{dc}}\right)\right]$. The current through diode $\mathrm{D}_{21}$ starts decrease and therefore diodes $\mathrm{D}_{21}$ and $\mathrm{D}_{22}$ turned on simultaneously and hence the $2^{\text {nd }}$ transformer output voltage is clamped to zero as shown in Figure 5.

\section{Mode 3 (t2-t3):}

From figure 6 , at time $t=t_{2}$, the capacitor $C_{2}$ is completely discharged to zero. So, the body diode of $\mathrm{S}_{2}$ is on. Therefore the device $S_{2}$ is ready to function under ZVS at the ending of time $\mathrm{t}=\mathrm{t}_{2}$.

\section{Mode 4 (t3-t4):}

From figure 7, the device $S_{2}$ is turned on under ZVS at time $t=t_{3}$. The sum of primary currents $i_{p 2}$ and $i_{p 3}$ are flows through the device $S_{2}$.

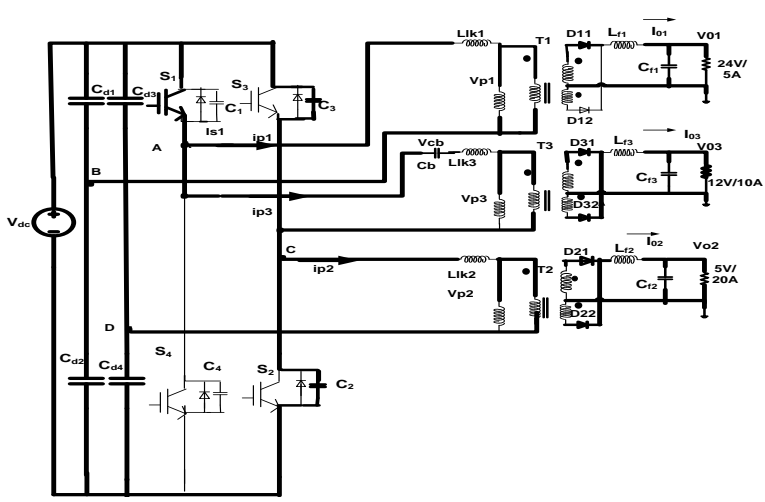

Figure 5: Mode '2' operation

Mode 5 (t4-t5):

From figure 8, during this mode, the current flowing through diode $\mathrm{D}_{21}$ rises to the second output current and current flowing through diode $\mathrm{D}_{22}$ falls to zero at time $\mathrm{t}=\mathrm{t}_{4}$.

\section{Mode 6 (t5-t6):}

From figure 9, during this mode, the current flowing through diode $\mathrm{D}_{31}$ rises to third output current and current flowing through $\mathrm{D}_{32}$ falls to zero at time $\mathrm{t}=\mathrm{t}_{5}$. 


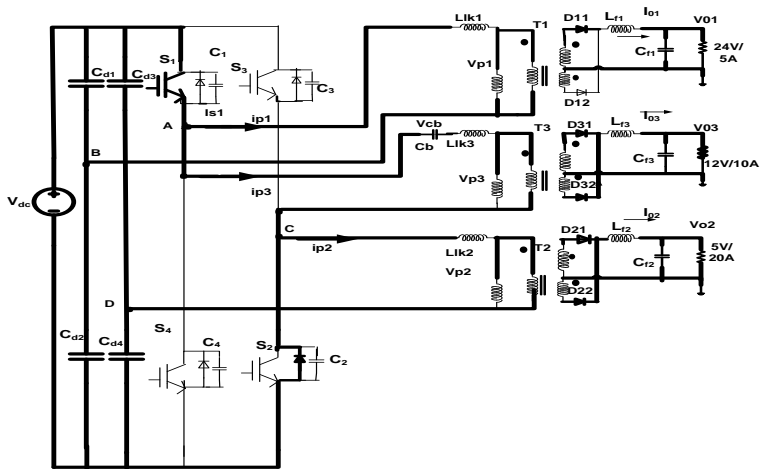

Figure 6: Mode '3' operation

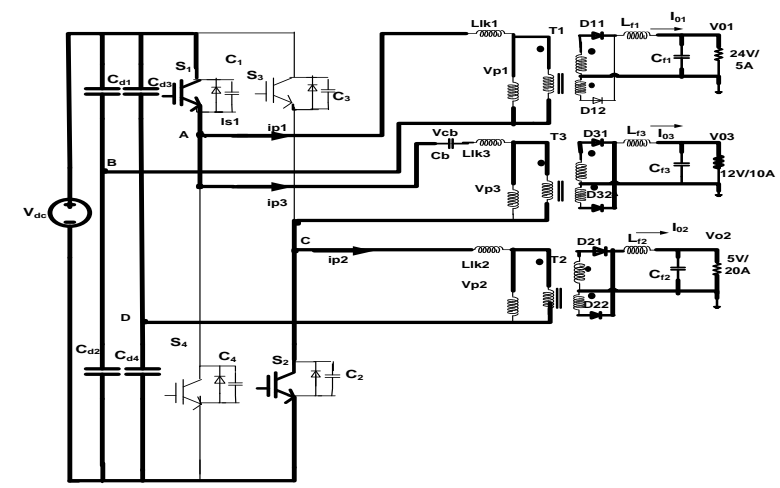

Figure 7: Mode '4' operation

Mode 7 (t6-t7):

From figure 10, the device $S_{1}$ is turned off under ZVS at time $t=t_{6}$. The sum of currents $i_{P 1}$ and $i_{P 3}$ will charge thecapacitor $\mathrm{C}_{1}$ and discharge capacitor $\mathrm{C}_{4}$.

\section{Mode 8 (t7-t8):}

The voltage across capacitor $\mathrm{C}_{4}$ is discharged to $\left[\mathrm{k}_{1} \cdot \mathrm{V}_{\mathrm{dc}}\right]$ at time $\mathrm{t}=\mathrm{t}_{7}$. The voltage $\mathrm{V}_{\mathrm{AB}}$ becomes zero due to voltage $\left[\mathrm{k}_{1} . \mathrm{V}_{\mathrm{dc}}\right]$ across capacitor $\mathrm{C}_{4}$. Thereby, the current flowing through diode $\mathrm{D}_{12}$ starts rising from zero value, whereas the current flowing through $\mathrm{D}_{11}$ starts falling. Hence the diodes $\mathrm{D}_{11}$ and $\mathrm{D}_{12}$ are conducting simultaneously and voltage of transformer 1 is clamped to zero, as shown in Figure 11.

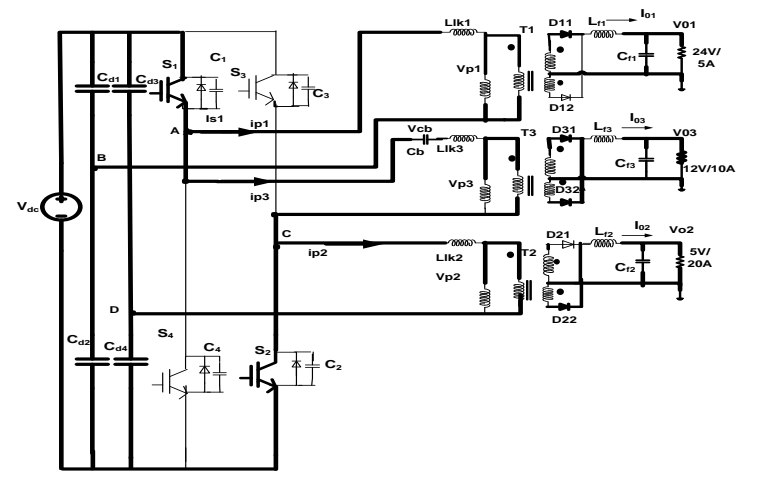

Figure 8: Mode '5' operation

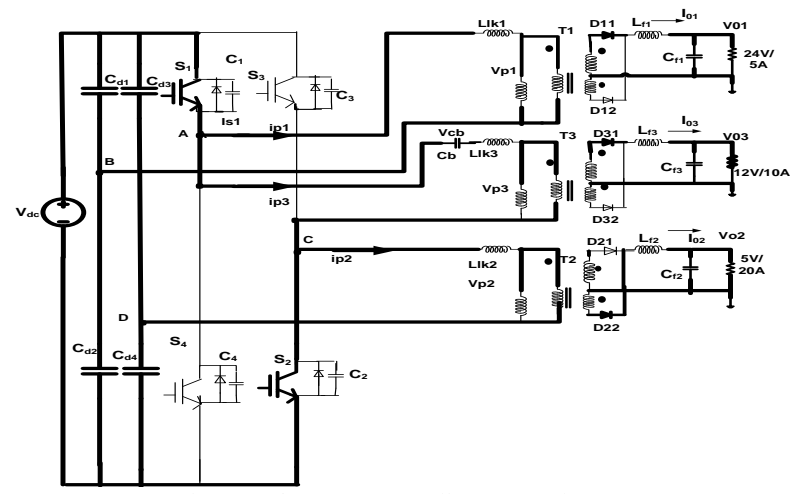

Figure 9: Mode '6' operation

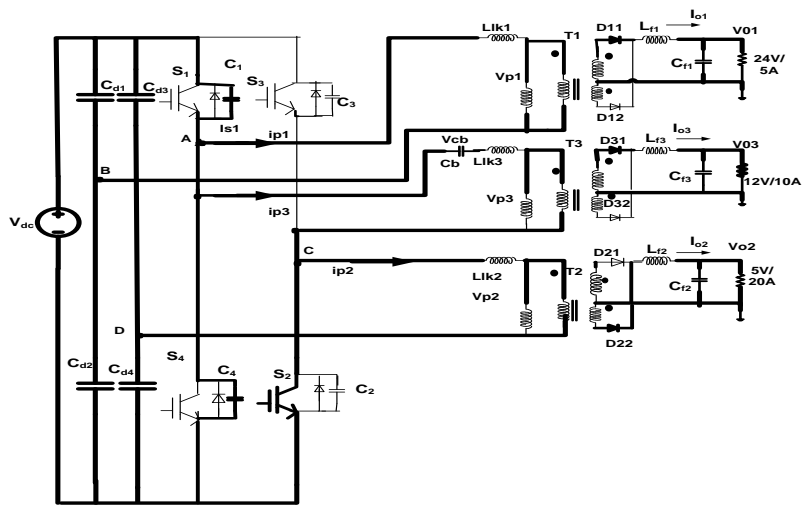

Figure 10: Mode '7' operation

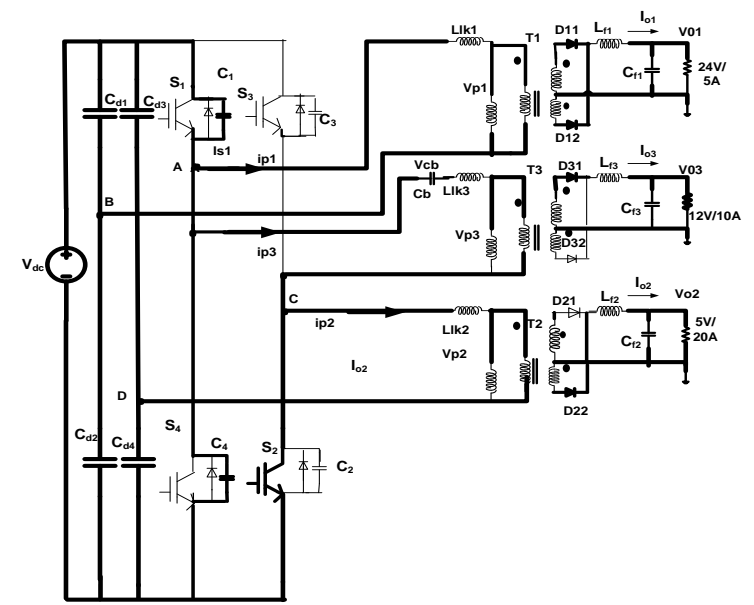

Figure 11: Mode '8' operation

\subsection{Realization of soft switching:}

The devices $\mathrm{S}_{1} \& \mathrm{~S}_{4}$ are operating under ZVS based on the energy in the output inductance of third output. The control devices $S_{3}$ and $S_{2}$ are operating under ZVS based on energy stored in leakage inductances of transformers 2 and 3.

The following ZVS condition must satisfy

$$
\begin{gathered}
\quad\left[\frac{1}{2} L_{\mathrm{lk} 2} \cdot\left\{\frac{\left(2 \cdot I_{O 2} \cdot k_{2}\right)}{N_{T 2}}\right\} \cdot\left\{\frac{\left(2 \cdot I_{O 2} \cdot k_{2}\right)}{N_{T 2}}\right\}+\frac{1}{2} L_{\mathrm{lk} 3} \cdot\left\{\frac{I_{O 3}}{N_{T 3}}\right\} \cdot\left\{\frac{I_{O 3}}{N_{T 3}}\right\}\right]> \\
C_{\mathrm{r}} \cdot\left\{1-\mathrm{k}_{2}\right\} \cdot\left\{1-\mathrm{k}_{2}\right\}\left\{V_{d c}^{2}\right\} \\
\text { Where } \mathrm{C}_{\mathrm{r}} \text { is the parasitic capacitance, }
\end{gathered}
$$
$\mathrm{C}_{1}=\mathrm{C}_{2}=\mathrm{C}_{3}=\mathrm{C}_{4}=\mathrm{C}_{\mathrm{r}}$.

\subsection{Design equations:}

The converter design indicates the design of values for $\mathrm{C}_{\mathrm{d} 1}, \mathrm{C}_{\mathrm{d} 2}, \mathrm{C}_{\mathrm{d} 3}, \mathrm{C}_{\mathrm{d} 4}, \mathrm{C}_{1}, \mathrm{C}_{2}, \mathrm{C}_{3}, \mathrm{C}_{4}, \mathrm{C}_{\mathrm{b}}, \mathrm{L}_{\mathrm{lk}}, \mathrm{L}_{\mathrm{f}}$ and $\mathrm{C}_{\mathrm{f}}$. The output inductor should be large enough to make the output current

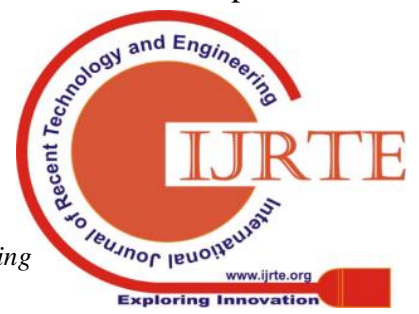


should be continuous throughout the switching period and leakage inductance of transformer must be small enough to make the less reset time.

The capacitors $\mathrm{C}_{\mathrm{d} 1}, \mathrm{C}_{\mathrm{d} 2}, \mathrm{C}_{\mathrm{d} 3}$ and $\mathrm{C}_{\mathrm{d} 4}$ must be large enough to make the voltage division must be maintained as constant even when the change of input voltage and voltage spikes produced by the device capacitances.

The resonant capacitor $\mathrm{C}_{\mathrm{r}}\left(=\mathrm{C}_{1}=\mathrm{C}_{2}=\mathrm{C}_{3}=\mathrm{C}_{4}\right)$ must be selected in such a way that the minimum requirement for ZVS operation of control device during turn-off. The large capacitance is required to hold the device voltage closed to zero at time $t_{\mathrm{fi}}$. The value of $\mathrm{t}_{\mathrm{fi}}$ can be taken from the data sheet. The value of $\mathrm{C}_{\mathrm{r}}$ can e calculated as,

$\mathrm{C}_{\mathrm{r}}=\frac{\mathrm{t}_{\mathrm{fi}} * \mathrm{I}_{\mathrm{p}}}{\mathrm{V}_{\mathrm{dc}}}$

The dc output filter elements are designed based on the following equations:

$$
\begin{aligned}
& \Delta \mathrm{I}_{\mathrm{O}}=\frac{\mathrm{V}_{\mathrm{O}} *(1-\mathrm{k}) * \mathrm{~T}_{\mathrm{S}}}{\mathrm{L}_{\mathrm{f}}} \\
& \frac{\Delta \mathrm{V}_{\mathrm{O}}}{\mathrm{V}_{\mathrm{O}}}=\frac{\pi^{2} *(1-\mathrm{k}) * f_{r}^{2}}{f_{S w}^{2}} \\
& \mathrm{f}_{\mathrm{r}}=\frac{1}{2 * \pi * \sqrt{\mathrm{L}_{\mathrm{f}} * \mathrm{C}_{\mathrm{f}}}}
\end{aligned}
$$

Where $\Delta \mathrm{V}_{\mathrm{O}} \& \Delta \mathrm{I}_{\mathrm{O}}$ are the acceptable ripple contents in the dc output voltage and current waveforms, $V_{O}$ is the required dc output voltage, $f_{r}$ is the resonant frequency, $\mathrm{f}_{\mathrm{sw}}=\left(1 / \mathrm{T}_{\mathrm{s}}\right)$ is the switching frequency and $\mathrm{k}$ is the duty cycle of device.

\section{RESULTS AND DISCUSSION}

Figure 12 show the gate voltage, voltage across and current through device $S_{1}$ for the device transition period from off state to on state. When the gate pulse is given to $S_{1}$, then the device $S_{1}$ is turned on and current passes through the device from time $t=7.3085 \mathrm{~ms}$, it is observed that the voltage across device is still zero, so no device power loss during transient instant from off state to on state and therefore ZVS is achieved for $S_{1}$. The ZVS is developed across $S_{1}$ due to clamped to zero by the body diode $D_{1}$. Hence, the device $S_{1}$ is turning on under ZVS during off to on transient period. The device is completely turned on at time $t=7.3095 \mathrm{~ms}$, then the collector current of $\mathrm{S}_{1}$ is starts rising from zero to $1.3 \mathrm{~A}$ and the collector to emitter voltage of $S_{1}$ is clamped to zero due to its intrinsic capacitors $\mathrm{C}_{1}$.

Figure 13 show the gate voltage, voltage across and current through device $S_{1}$ during on state to off state transition period. The gate pulse is given to $S_{1}$ at time $7.3475 \mathrm{~ms}$, but the collector current of $S_{1}$ starts falling from $6 \mathrm{~A}$ to zero from the instant $7.348 \mathrm{~ms}$ to $7.3485 \mathrm{~ms}$ and the collector to emitter voltage of $S_{1}$ is still clamped to zero due to its intrinsic capacitors $C_{1}$. Therefore, the device $S_{1}$ is operating under ZVS during on to off transition instant. The device $S_{1}$ is completely turned off at time $t=7.35 \mathrm{~ms}$, then the collector-emitter voltage of $S_{1}$ is starts rising from zero to rated input voltage due to charging of its intrinsic capacitor $\mathrm{C}_{1}$. Thus, the device power loss becomes zero in on state to off state transition instant.
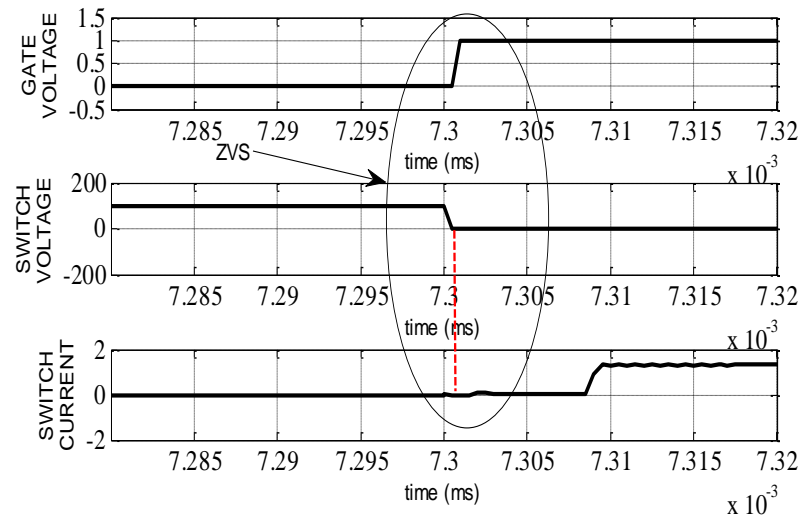

Figure 12: Gate voltage, voltage across and current through $S_{1}$ during $O F F$ to $O N$
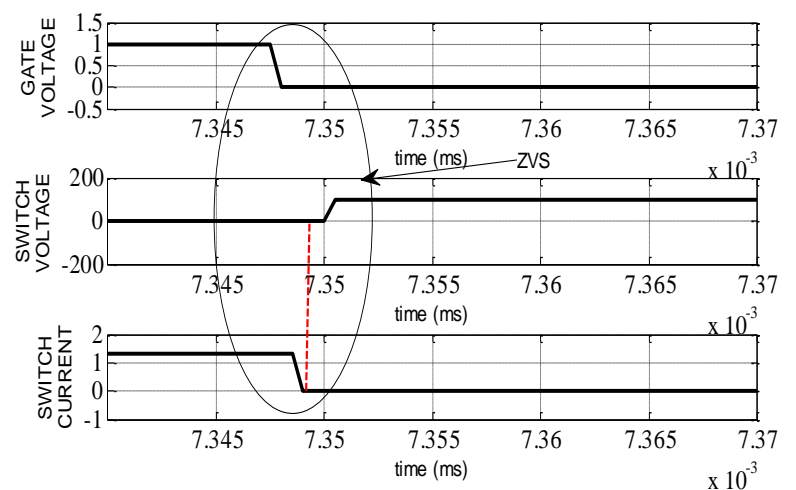

Figure 13: Gate voltage, voltage across and current through $S_{1}$ during $O N$ to $O F F$

Figure 14 show the filtered three dc output voltage waveforms of the proposed converter. The dc filter values are designed in such a way that the ripple content present in dc output voltage waveforms become less than $3 \%$. This converter converts input dc voltage of $100 \mathrm{~V}$ into $24 \mathrm{~V}, 12 \mathrm{~V}$ and $5 \mathrm{~V}$ respectively and these output voltages are reached to their steady state settling values at time $\mathrm{t}=0.45 \mathrm{~s}$.
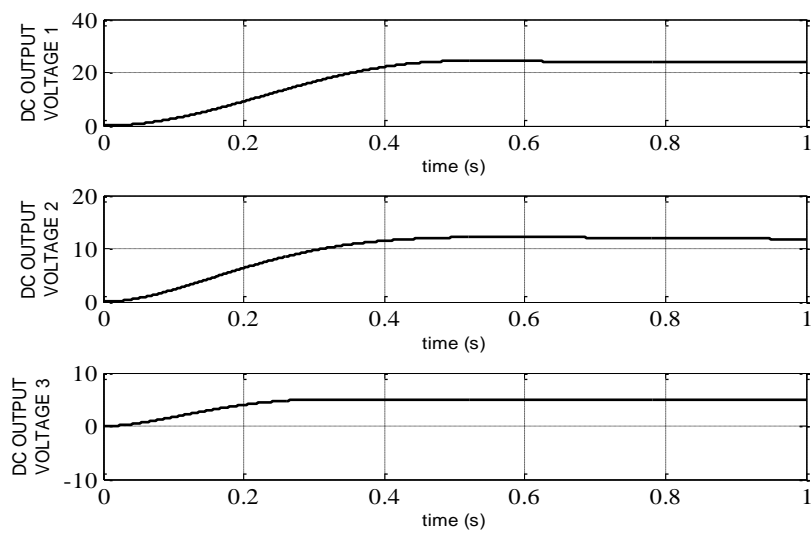

Figure 14: Three controlled dc output voltages with filter

Table 2 shows the $\%$ efficiencies of the proposed single input three output two level DC-DC converter for different load currents at the second load output with $\mathrm{V}_{\mathrm{o} 2}=5 \mathrm{~V}$. 


\section{RESEARCH ON SINGLE INPUT AND REGULATED MULTIPLE OUTPUT ISOLATED DC-DC SOFT DEVICEING CONVERTER}

Table 2: Comparison of efficiencies of proposed converter for various load currents at the second load

output

\begin{tabular}{|c|c|c|c|c|}
\hline $\begin{array}{c}\text { S. } \\
\text { NO }\end{array}$ & $\begin{array}{c}\text { LOAD } \\
\text { CURREN } \\
\text { T } \\
\text { (Amps) }\end{array}$ & $\begin{array}{c}\text { OUTP } \\
\text { UT } \\
\text { POWER } \\
\text { (Watts }\end{array}$ & $\begin{array}{c}\text { INPU } \\
\text { POW } \\
\text { ER } \\
\text { (Watt } \\
\text { s) }\end{array}$ & $\begin{array}{c}\text { EFFICIEN } \\
\text { CY }\end{array}$ \\
\hline 1 & 5 & 25.7 & 33.16 & 77.5 \\
\hline 2 & 7 & 35.2 & 44.38 & 79.3 \\
\hline 3 & 9 & 44.7 & 53.21 & 84 \\
\hline 4 & 11 & 54.2 & 62.87 & 86.2 \\
\hline 5 & 13 & 64.1 & 73.25 & 87.5 \\
\hline 6 & 15 & 73.9 & 82.75 & 89.3 \\
\hline
\end{tabular}

\section{CONCLUSION}

In this paper, the two-level single input multiple output isolated DC-DC converter was implemented for generating three multiple controlled dc output voltages from single dc voltage source. This topology generates $(2 n-1)$ outputs, where ' $n$ ' is the number of legs. Due to soft switching mechanism, the proposed multiple output DC-DC converter gives higher efficiency even at high switching frequency. The operational modes, design equations and realization of soft switching of the proposed converter were discussed. The performance of the proposed was analyzed and results are quite satisfied.

\section{. REFERENCES}

1. C.-C. Wen, C.-L. Chen, W. Chen, and J. Jiang, "Magamp Post Regulation for Flyback Converter," in Proc. IEEE Power Electron. Spec.Conf., Jun. 17-22, 2001, pp. 333-338.

2. Zhiqiang Guo, Deshang Sha and Xiaozhong Liao, "Hybrid Phase-Shift-Controlled Three-Level and LLC DC-DC Converter With Active Connection at the Secondary Side," IEEE Trans. Power Electron., vol. 30, no. 6, pp. 2985-2996, June. 2015.

3. Y.-T. Chen, Y. Dan, and Chen, "Small-signal modeling of magnetic amplifier post regulators with current-mode control," IEEE Trans. Ind. Appl., Vol. 47, no. 4, pp. 722-728, Aug. 2000.

4. H. Hamada and M. Nakaoka, "Analysis and design of a saturable reactor assisted soft- switching full-bridge dc-dc converter," IEEE Trans. Power Electron., Vol. 9, no. 3, pp. 309-317, May 1994.

5. Y. Xi and P. K. Jain, "A forward converter topology with independently and precisely controlled multiple outputs," IEEE Trans. Power Electron., Vol. 18, no. 2, pp. 648-658, Mar. 2003.

6. J. Zhang, F. Zhang, X. Xie, D. Jiao, and Z. Qian, "A novel ZVS dc-dc converter for high power applications," IEEE Trans. Power Electron., Vol. 19, no. 2, pp. 420-429, Mar. 2004

7. S. Chakraborty, A. K. Jain, and N. Mohan, "A novel converter topology for multiple individually controlled outputs," IEEE Trans. Power Electron., Vol. 21, no. 2, pp. 361-369, Mar. 2006.

8. T. Mishima and M. Nakaoka, "Practical evaluations of A
ZVS-PWM DC-DC converter with secondary-side phase-shifting active rectifier," IEEE Trans. Power Electron., Vol. 57, no. 99, pp. 1-12, Oct. 2011.

9. Zhiqiang Guo, Kai Sun and Deshang Sha, "Improved ZVS Three-level DC-DC Converter with Reduced Circulating Loss," IEEE Trans. Power Electronics., vol. 39, no. 9, pp.6394-6404, 2016.

10. H. E. Tacca, "Single-device two-output flyback-forward converter operation," IEEE Trans. Power Electron., Vol. 13, no. 5, pp. 903-911, Sep. 1998.

11. A. Ferreres, J. A. Carrasco, E. Maset, and J. B. Ejea, "Small-signal modeling of a controlled transformer parallel regulator as a multiple output converter high efficient post-regulator," IEEE Trans. Power Electron., Vol. 19, no. 1, pp. 183-191, Jan. 2004.

12. A. Barrado, E. Olias, A. Lazaro, J. Pleite, and R. Vazquez, "PWM-PD multiple output dc-dc topologies: Operation and control loop modeling," IEEE Trans. Power Electron., Vol. 19, no. 1, pp. 140-149, Jan. 2004. 